Article

\title{
Scrutinizing Virtual Citizen Involvement in Planning: Ten Applications of an Online Participatory Tool
}

\author{
Mattias Hjerpe *, Erik Glaas and Sofie Storbjörk \\ Centre for Climate Science and Policy Research, Department of Thematic Studies-Environmental Change, Linköping \\ University, 58183 Linköping, Sweden; E-Mails: mattias.hjerpe@liu.se (M.H.), erik.glaas@liu.se (E.G.), \\ sofie.storbjork@liu.se (S.S.) \\ * Corresponding author
}

Submitted: 16 March 2018 | Accepted: 14 June 2018 | Published: 28 September 2018

\begin{abstract}
How to organize citizen participation in planning is continuously debated. The amount of Online Participatory Tools (OPTs) to facilitate inclusive and efficient participation has increased. While studies have assessed their functionality, usability and effectiveness in planning, they have rarely analyzed OPTs beyond single-cases, targeted tools that are widely used or assessed how OPTs affect broader values of participation. Targeting this absence, this study analyzes how ten applications of a widely used OPT, CityPlanner ${ }^{\mathrm{TM}}$, affect the normative, substantive and instrumental values of citizen participatory planning in Swedish cities. By analyzing 1,354 citizen proposals and interviewing urban planners, we find that citizens more extensively submit proposals and initiate debates on planning when using the OPT. Results suggest a more even age and gender distribution among proposal users than with conventional methods, facilitating normative values of participation. The OPT was generally applied early in planning and generated high-quality inputs. Our results, however, nuance previous analyses by also emphasizing the importance of place-specificity of OPT applications and of joint participation strategies among departments. Key for OPT development includes the need to improve their ability to analyze overarching trends among inputs.
\end{abstract}

\section{Keywords}

citizen participation; governance; online participatory tools; planning; visualization

Issue

This article is part of the issue "Multidisciplinary Studies" in Politics and Governance.

(C) 2018 by the authors; licensee Cogitatio (Lisbon, Portugal). This article is licensed under a Creative Commons Attribution 4.0 International License (CC BY).

\section{Introduction}

Citizen participation in planning is a recurrent research topic. Among the highlighted gains are normative, substantive, and instrumental values (Fiorino, 1989; Stirling, 2006, 2008). As Fung (2006, p. 74) argues, "citizens can be the shock troops of democracy. Properly deployed, their local knowledge, wisdom, commitment, authority, even rectitude can address wicked failures of legitimacy, justice, and effectiveness in representative and bureaucratic institutions".

How to mobilize citizen participation in planning is critical. Previous studies contend that citizen participation has an instrumental role as purely input gathering, leading to limited efficiency and exclusion of perspectives (Michels \& De Graaf, 2010). Further, policy-makers and planners are reluctant to include citizen perspectives due to uncertain effects on actual planning (Blunkell, 2017), and the fact that obvious barriers such as lack of resources and competence, as well as inadequate and illtimed participation methods, can constrain constructive discussion (Conrad, Cassar, Christie, \& Fazey, 2011). As a result, citizen participation has not increased substantially, despite its known benefits (Georgiadou \& Stoter, 2010; Poplin, 2012).

To address these aforementioned constraints, the number and use of Online Participatory Tools (OPT) have increased substantially (Afzalan, Sanchez, \& Evans- 
Conley, 2017). OPTs often utilize advancements in Public Participatory GIS, including geotagged questionnaires (Czepkiewicz, Jankowski \& Mlodkowski, 2017; Jankowski, Czepkiewicz, Mlodkowski, \& Zwolinski, 2016) and data visualization techniques used in Planning Support Systems (Russo, Lanzilotti, Costabile, \& Pettit, 2018), to broaden the scope of participation by engaging more citizens in providing input on local planning (Afzalan et al., 2017).

Though research into the functionality, usability and influence of OPTs has progressed, studies have rarely analyzed OPTs beyond single-cases, looked at tools that are widely used or how OPTs affect broader values of participation. Consequently, studies are needed which use more comprehensive evaluation frameworks and which discuss the organizational implementation of the OPT (Kahila-Tani, Broberg, Kyttä, \& Tyger, 2016). Arguably, this is key for improving the use of OPTs since "their inappropriate use can result in problems, such as instrumental use of citizens' mass participation" (Afzalan et al., 2017).

This study targets this need by analyzing how ten applications of a widely used OPT effect the normative, substantive and instrumental values of citizen participatory planning in Swedish cities, discussing the pros and cons of using OPTs in local planning. Specifically, the study analyses 1,354 proposals retrieved from ten applications of the OPT CityPlanner ${ }^{\mathrm{TM}}$ and interviews with urban planners who have worked with CityPlanner ${ }^{\mathrm{TM}}$. The research is conducted in an interdisciplinary project addressing both technical and governance aspects of participatory planning. Research questions (RQs) are:

1. How can OPT deliberations influence normative values of participatory planning?

2. How does the OPT influence the substantive quality of citizen inputs?

3. Does the OPT create risks for instrumental interpretations of citizen inputs?

4. How does the use of OPTs in planning impact the division of roles between citizens, planners, and politicians?

The article is structured as follows: section two presents the analytical framework, outlining three potential values of citizen participation. Section three and four present the research methods, the OPT, and the ten applications. Section five discusses the main findings in accordance with RQs 1-3. Section six concludes and elaborates on RQ4 and the pros and cons of using OPTs in planning.

\section{Analytical Framework}

To enable a broad analysis of the CityPlanner ${ }^{\mathrm{TM}} \mathrm{OPT}$, the article builds on a framework outlining three categories of potential values for citizen participation, aligned with findings from research on digital tools for citizen participation. Such tools have different purposes including supporting learning and debate among citizens, monitoring by data collection, guiding citizen choices, or collection of and dialogue on citizen suggestions regarding strategic planning and development. The tool analyzed in this study relates to the latter type, comprising people-centric strategic planning tools (Ertiö, 2015), found to support and/or undermine participatory values as below.

\subsection{Values of Citizen Participation}

An often-used outline of potential values of citizen participation distinguishes between normative, substantive and instrumental values (Fiorino, 1989; Stirling, 2006, 2008).

\subsubsection{Normative Values}

Normative values emphasize citizen participation as an end-in-itself, i.e., direct gains of inclusive participatory processes (Stirling, 2006, 2008). Regarding the democratic effects, a long-standing question concerns whether direct participation in planning circumvents representative democracy, where elected politicians make decisions informed by expert judgements. Though we do not address this question directly, many empirical studies highlight that citizen participation is, indeed, political, but does not necessarily undermine current democratic processes. Rather, participation is a complement (Fung, 2006) and a precondition for increasing the plurality of stakes, empowering groups who often are not well provided for by local governance (Burby, 2003; Legacy, 2017). Thus, democratic aspects of participation provide a rigid foundation for decision-making by strengthening social justice, giving more citizens a voice in, and knowledge about, the decisions which affect them (Fung, 2015).

Previous studies have found that OPTs are promising for attracting new and more diverse citizen groups (Kahila-Tani et al., 2016; Schulz \& Newig, 2015). However, to become more "inclusive, just, and communicative", OPTs should arguably be more aligned with standardized local planning processes, address empowerment and consider the capacities and need of citizens (Afzalan et al., 2017; Kleinhans, Van Ham, \& Evans-Conley, 2015). Moreover, OPT usage also risks over-representing internet-savvy groups, constraining equal representation (Czepkiewicz et al., 2017; Schulz \& Newig, 2015).

\subsubsection{Substantive Values}

Substantive values emphasize citizen participation as the means-to-an-end, i.e. improving governance by enhancing the quality of decisions (Stirling, 2006). This includes finding well-suited solutions to problems by obtaining a better understanding of local contexts and collecting constructive proposals from citizens, which affect policy and planning outcomes (Fung, 2015). Planning can better 
align with local conditions if planners improve their understanding of what citizens' highlight and value, thereby improving both the effectiveness (addressing the "right" issues) and efficiency (addressing issues the optimal way) of plans (Faehnle, Bäcklund, Tyrväinen, Niemelä, \& YliPelkonen, 2014).

OPTs present opportunities for local governments to obtain qualitative inputs from citizens on e.g. how to improve maintenance (Ertiö, 2015). Applying OPTs early on in planning appears particularly promising since it facilitates efficient collection of inputs and fosters trust in planning (Kahila-Tani et al., 2016). Due to the lack of assessments, however, the usefulness of OPTs for participatory planning remains largely unclear (Brown \& Kyttä, 2014). To further improve OPTs, functions for analysing and reporting on aggregated inputs gained from citizens are important (Jankowski et al., 2016).

\subsubsection{Instrumental Values}

Instrumental values relate to opportunities for justifying pre-decided plans or decisions based on citizen inputs (Stirling, 2006, 2008), or to the practice of only collecting inputs for a specific cause (Michels \& De Graaf, 2010). The former includes either strong justification, where participatory deliberation is set-up to justify a desired plan or policy, or weak justification, where citizen inputs are summarized to allow for flexibility in justifying a decision as "legitimate" and thereby manage blame (Stirling, 2008). Instrumental aspects can be considered as false participation, where participation does not influence decisions, raising issues of legitimacy and transparency. Fung (2006, p. 70) argues that "a public policy or action is legitimate when citizens have good reasons to support or obey it", which they would if: "public opinion and will" were sufficiently taken into account, inputs were used in a transparent way, and if the rationale for participation was clear.

For OPTs, as with conventional forms of deliberation, there is a risk that planners marginalize some voices, while promoting more powerful interests (Kleinhans et al., 2015). To further develop OPTs, it is necessary to find more transparent ways to report back on how citizenprovided inputs are used or considered (Kahila-Tani et al., 2016) necessitating further developments to allow citizens to take part in data analysis (Ertiö, 2015).

\subsection{Operationalizing the Analytical Framework}

To analyze applications of the OPT Cityplanner ${ }^{\mathrm{TM}}$, a series of detailed inquiries corresponding to sub-categories of the three types of values of citizen participation were applied (Table 1). The inquiries were addressed by the combination of research methods and material presented in section three.

\section{Methods and Materials}

The study builds on analyses of ten applications of the OPT CityPlanner ${ }^{\mathrm{TM}}$ applied in five Swedish municipalities

Table 1. Operationalization of the normative, substantive, and instrumental values of citizen participation for analysis of OPT proposals and interviews with urban planners.

\begin{tabular}{|c|c|c|}
\hline Value & OPT proposals & Urban planners \\
\hline \multicolumn{3}{|l|}{ Normative } \\
\hline $\begin{array}{l}\text { Democracy: do citizens } \\
\text { provide input on plans? }\end{array}$ & $\begin{array}{l}\text { What amount of proposals are } \\
\text { obtained via the OPT compared to } \\
\text { conventional deliberations? }\end{array}$ & $\begin{array}{l}\text { Do OPT deliberations attract more } \\
\text { citizens to participate? }\end{array}$ \\
\hline $\begin{array}{l}\text { Empowerment: are commonly } \\
\text { overlooked groups reached? }\end{array}$ & $\begin{array}{l}\text { What are the proposal submitters' } \\
\text { gender and age? }\end{array}$ & $\begin{array}{l}\text { Does the OPT attract citizen groups } \\
\text { which are hard to reach with } \\
\text { conventional deliberations? }\end{array}$ \\
\hline $\begin{array}{l}\text { Learning: do deliberations create } \\
\text { opportunities for learning? }\end{array}$ & $\begin{array}{l}\text { Does the OPT spur debate or } \\
\text { knowledge exchange among users? }\end{array}$ & $\begin{array}{l}\text { Have any additional learning activities } \\
\text { been initiated when applying the OPT? }\end{array}$ \\
\hline \multicolumn{3}{|l|}{ Substantive } \\
\hline $\begin{array}{l}\text { Efficiency: can planning utilize } \\
\text { citizen suggestions? }\end{array}$ & $\begin{array}{l}\text { Do OPT proposals contain practical } \\
\text { suggestions on planning? }\end{array}$ & $\begin{array}{l}\text { To what extent has citizen suggestions } \\
\text { via the OPT been used in planning? }\end{array}$ \\
\hline $\begin{array}{l}\text { Context: are important } \\
\text { contextual factors targeted? }\end{array}$ & $\begin{array}{l}\text { Do OPT proposals address contextual } \\
\text { factors that can facilitate planning? }\end{array}$ & $\begin{array}{l}\text { To what extent can citizen inputs } \\
\text { outside of the question posed in the } \\
\text { OPT be included in planning? }\end{array}$ \\
\hline
\end{tabular}

Instrumental

Justification: are citizen inputs used transparently?
Do the OPT applications specify how inputs are used?
Have any systems for feedback to citizens or collective analyses been applied? 
and on semi-structured interviews with ten planners in Norrköping municipality, where this tool has been most extensively used.

Citizen proposals were retrieved from the municipal planning offices in the form of PDF-files or Excelspreadsheets. Firstly, for each application the following data was summarized:

- The total number of proposals.

- The gender and age distribution of the proposalsubmitters.

- The number of comments that a proposal received.

The above aspects were used to analyze the democracy, empowerment and learning components, respectively (Table 2). Though further information, such as socioeconomic and cultural background, are also relevant for empowerment, such information was not available but was covered by the interviews. Secondly, each proposal was classified as follows:

- The topic that the proposal primarily addresses.

- What the proposal aimed to change/develop.

- What type of inputs the proposal included.

These were used to analyze the efficiency and contextual elements of the proposals (Figure 2 and Table 3). Thirdly, to analyze instrumental values, the introduction and the questions posed via the Cityplanner ${ }^{\mathrm{TM}}$ webinterface were scrutinized on whether they explicitly specified how proposals are used in planning (Table 2). Fourthly, the number of proposals submitted by citizens when using conventional planning procedures in similar planning contexts in the included municipalities were retrieved (see details in Table 2)
Additionally, ten planners in Norrköping with experience of using Cityplanner ${ }^{\mathrm{TM}}$ were interviewed to gain qualitative insights into:

- How the OPT has been used.

- Whether the OPT attracted wider citizen representation.

- If and how learning is explicitly targeted.

- How inputs are scrutinized and acted upon.

- The risk of instrumental interpretations of proposals.

The interviews were semi-structured to allow for followup questions and deviations in the discussions and lasted 1-1.5 hours. The questions related to the interviewee's opinion on the different aspects of normative, substantial and instrumental values. All interviews were audiorecorded and transcribed. The interview transcripts were firstly analyzed individually, followed by meaning concentration of reoccurring statements and perspectives. The validity of the analysis is strengthened by comparing statements, both among the planners, and by contrasting their views with the results of the quantitatively oriented categorization of proposals.

\section{Ten Applications of the OPT CityPlanner ${ }^{\mathrm{TM}}$}

The ten analyzed applications all build on the CityPlanner ${ }^{\mathrm{TM}}$ platform (Figure 1) developed by the Swedish software company Agency9. The OPT comprises 3D visualizations of cities, where citizen dialogue is an add-on component enabling municipalities to pose questions to citizens on contemporary planning issues. Citizens comment through a map interface. As the company states, the OPT is designed to involve stakeholders and citizens in early dialogue, crowd-source ideas for urban devel-

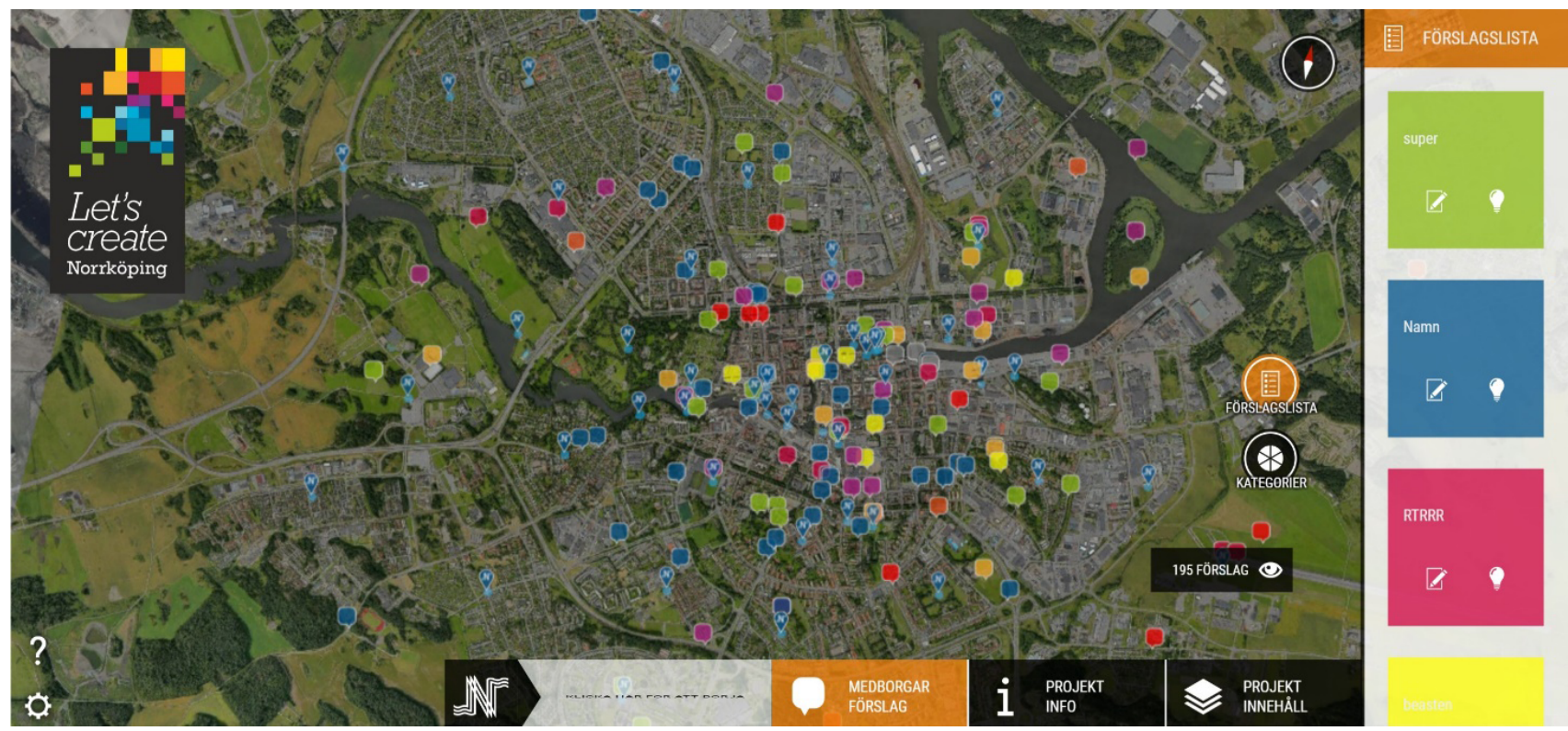

Figure 1. Graphical interface of the Cityplanner ${ }^{\mathrm{TM}}$ tool as applied in Norrköping. 
COGITATIO

Table 2. Description of the ten applications of the CityPlanner ${ }^{T M}$ OPT concerning type, time, timing, what the proposals feed into, number of proposals submitted, share of proposals submitted by women, and the average number of comments per proposal.

\begin{tabular}{|c|c|c|c|c|c|c|c|c|c|}
\hline Application & Process/Project & Topic & Location & Timing & Output & $\begin{array}{l}\text { Number of } \\
\text { proposals } \\
\text { via the OPT }\end{array}$ & $\begin{array}{l}\text { Number of proposals } \\
\text { via conventional } \\
\text { planning procedures* }\end{array}$ & $\begin{array}{l}\text { Share of proposals } \\
\text { submitted by } \\
\text { women }\end{array}$ & $\begin{array}{l}\text { Number of } \\
\text { comments } \\
\text { per proposal }\end{array}$ \\
\hline Avesta-Krylbo & Formal planning & Ecovillage & District-level & Early & In proposal & 74 & 44 & $24 \%$ & 1.1 \\
\hline Koppardalen/Avesta & Formal planning & General & District-level & Early & In proposal & 17 & 2 & $41 \%$ & 3.0 \\
\hline Fagersta & Formal planning & General & District-level & Early & In proposal & 66 & 48 & $15 \%$ & 3.6 \\
\hline Årummet/Falun & $\begin{array}{l}\text { Informal urban } \\
\text { development }\end{array}$ & General & City Centre & Early & Unspecified & 226 & 29 & $62 \%$ & 3.0 \\
\hline $\begin{array}{l}\text { Urban Vision/ } \\
\text { Norrköping }\end{array}$ & $\begin{array}{l}\text { Exhibition urban } \\
\text { development }\end{array}$ & General & Municipal-level & Ongoing & Unspecified & 162 & 23 & $44 \%$ & 3.1 \\
\hline $\begin{array}{l}\text { Trädgårdsstaden } \\
\text { Hageby/Norrköping }\end{array}$ & Informal & General & District-level & Idea & Unspecified & 150 & 5 & $58 \%$ & - \\
\hline $\begin{array}{l}\text { Framtidens resor/ } \\
\text { Norrköping }\end{array}$ & Informal & Mobility & Municipal-level & Early & $\begin{array}{l}\text { Project-internal } \\
\text { use }\end{array}$ & 25 & 8 & $23 \%$ & 0.8 \\
\hline $\begin{array}{l}\text { Sociotopkarta/ } \\
\text { Norrköping }\end{array}$ & Informal & Green space & Municipal-level & Early & $\begin{array}{l}\text { Project-internal } \\
\text { use }\end{array}$ & 58 & 0 & $69 \%$ & - \\
\hline Kolkajen/Stockholm & Formal planning & 5 topics & District-level & Early & Unspecified & 209 & 20 & $27 \%$ & 3.9 \\
\hline $\begin{array}{l}\text { Vision } \\
\text { Industrilandskapet/ } \\
\text { Norrköping }\end{array}$ & $\begin{array}{l}\text { Informal urban } \\
\text { development }\end{array}$ & General & City Centre & Idea & Unspecified & 367 & 23 & $28 \%$ & - \\
\hline All applications & - & - & - & - & - & $\begin{array}{l}\text { 1,354, } \\
\text { median: } 112\end{array}$ & $\begin{array}{l}\text { 202, } \\
\text { median: } 21.5\end{array}$ & Median: $42 \%$ & Median: 3.0 \\
\hline
\end{tabular}

* The number of citizen proposals submitted via conventional planning procedures were retrieved from similar local plans from the same municipality/jurisdiction. The following similar plans were used: Avesta-Krylbo: Comprehensive Plan Hedemora, 2015. Koppardalen/Avesta: Detailed Development Plan Boken 4, 2017. Fagersta: Comprehensive Plan Leksand, 2013. Årummet/Falun: Comprehensive Plan Falun-Borlänge, 2013. Urban Vision/Norrköping: Comprehensive Plan Norrköping, 2016. Trädgårdsstaden Hageby/Norrköping: Detailed Development Plan Oxelbergen 1:2, 2017. Framtidens resor/Norrköping: Detailed Development Plan Himmelstalund 1:1, 2017. Sociotopkarta/Norrköping: Detailed Development Plan Ingelstad ekbackarna, 2015. Kolkajen/Stockholm: Detailed Development Plan Värtan, 2015. Vision Industrilandskapet/Norrköping: Comprehensive Plan Norrköping, 2016. 
opment, gather local knowledge from people living in the area, and present key considerations and important questions for planning decisions.

This OPT has been used for different types of planning processes in the applications. These stretch from specific small-scale development projects to large-scale planning (Table 2).

\section{Results and Discussion}

The results are presented for each of the normative, substantive and instrumental value components. Quantitative data for the ten applications is mixed with illustrative perspectives provided by the interviews. Observations are discussed according to findings in previous studies.

\subsection{Normative Values}

The democratic value component was gauged by the volume of proposals submitted via CityPlanner ${ }^{\mathrm{TM}}$ in the ten applications. The median number of proposals per application was 112, ranging significantly from 17 to 367 . In five applications the number of proposals submitted exceeded 100 . This demonstrates that when invited, citizens submitted proposals to a high extent. The numbers of citizen-submitted proposals via conventional public consultation in similar planning applications were lower in all ten applications; in some instances, by a factor ten. The planners confirm that conventional public consultation resulted in fewer comments compared to the use of an OPT. This pattern exists even though Norrköping planning office has tested new forms of dialogue (although still physical consultations) to attract citizens such as bicycling dialogues and consultations on trams and exhibitions. A communicator at the municipal planning office found it generally difficult to attract people to physical consultations and noted that internal routines for online consultations were lacking: "I think it should be mandatory to send plans to the planning office to post online [e.g. via CityPlanner ${ }^{\mathrm{TM}}$ ]...that routine is missing today".

For empowerment, the compiled data enabled analysis of gender but not age. Only two applications contained age-data. Women submitted four proposals out of ten (both median and mean). However, the share of proposals submitted by women ranged considerably from $17 \%$ to $69 \%$. In terms of age, proposal-submitters in the Sociotopkarta application were evenly spread for those aged 20 to 64 . About $5 \%$ of the proposal submitters were younger than 20 years and $7 \%$ were older than 65 . In the Kolkajen application, the age distribution was skewed towards the 20 to 49 age group, from which three-quarters of all proposals were submitted. In that case, no proposals were submitted by the young and only $10 \%$ by the over 65s. Compared to previous research assessing conventional public consultation (Stenberg et al., 2013), these results show greater spread in both gender and age, further illustrating how hard it is to reach young people. Likewise, several planners contended that con- ventional consultations attracted only certain groups of citizens while underrepresenting others. According to a city architect:

Conventional planning processes, you know these various hearings, we all know who comes to these. Five middle-aged men go to all of them, but you miss entire citizen groups, women with foreign heritage who maybe don't speak the language, older people, younger people.

In line with previous studies (Kahila-Tani et al., 2016; Schulz \& Newig, 2015), our study suggests that this OPT has reached a more diverse group in terms of age as well as a more even balance between the genders. While generally seen as an enabler of diversified inputs, caution should be paid to new forms of citizen exclusion such as technical lockout of elderly people with low computer skills (Czepkiewicz et al., 2017). To avoid exclusion, the planners asserted that OPTs should complement physical hearings and be included as a routine in local planning (Afzalan et al., 2017). More routinized use of an OPT would require: learning both internally and for citizens about digital participation, method development for using OPT for outreach and new forms of OPT-facilitated dialogues that match emerging methods of planning.

For learning, citizens were able to indicate whether they liked or disliked the proposals submitted by other citizens in seven of the ten applications. Every proposal attracted on average 2.9 likes or dislikes (Figure 2); about $78 \%$ of them being likes (not displayed here). About $30 \%$ of the proposals attracted one or two likes/dislikes and another third went uncommented, while about $6 \%$ of the proposals received 10 likes/dislikes or more. This indicates that citizens not only submitted their own proposals via the OPT, but they also responded to other citizens' proposals. Planners, consequently, obtain a ranking of the most appreciated proposals which would not be automatically generated for proposals submitted through conventional consultations. Moreover, citizens sometimes added written comments on other proposals by adding their proposal beside it, also indicating an opportunity for learning and debate, as illustrated: "I agree to establish smaller buildings and a patio in the corner, as suggested"; "I agree with the previous speaker! Less traffic, more market-place trading and pavement cafés".

By showing how other citizens perceive and propose urban development, this OPT appears promising for visualizing the plurality of stakes, which Stenberg et al. (2013) viewed as a motor for democratic citizen deliberations and for facilitating learning by providing several alternative standpoints towards the challenges at hand. Even if the planners acknowledged this value of this OPT, they found that most citizens lack a basic understanding of formal planning processes to the extent that learning is constrained. To raise citizens' awareness the planners have therefore arranged planning exhibitions foremost at Norrköping Visualization Center, where the Cityplan- 


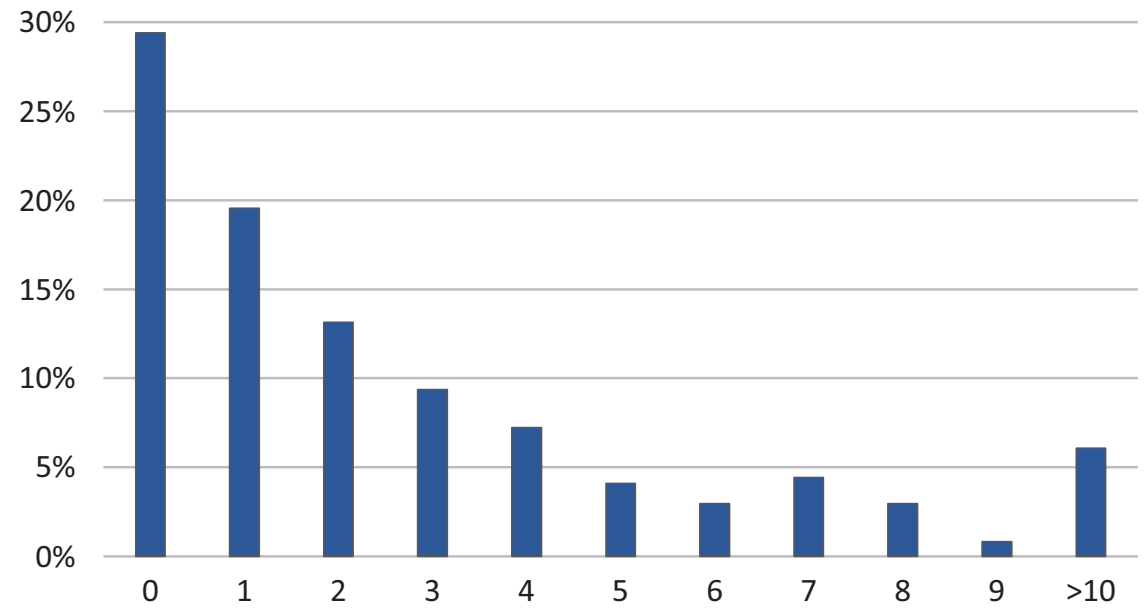

Figure 2. Percentages of proposals submitted via CityPlanner ${ }^{\mathrm{TM}}$ after the number of likes/dislikes they attracted $(n=607)$.

ner ${ }^{\mathrm{TM}}$ tool has been combined with visualizations of physical planning. While regarded as favourable for learning, the planners noted that citizen groups outside the educated middle-class rarely visited these exhibitions. Planners also suggest that information about citizen participation, physical preconditions and planning processes could be presented through this OPT. This would, however, need to be balanced against their current simplicity and user-friendliness.

\subsection{Substantive Values}

All proposals were categorized according to the topic addressed and what the citizens wanted to change/develop (Table 3). Proposals included a range of topics that citizens wanted to add or augment at a specific location thus providing a good representation of the planning context. Almost a quarter of the proposed changes related to traffic and streets. High proportions of traffic-related pro- posals were found in most applications, often promoting pedestrianism, cycling, and public transport. Many proposals suggested changes to make current traffic situations more compatible with other urban functions such as recreation. Proposals related to park and nature were found in similar proportions, $10-15 \%$ in all applications.

For efficiency, the four applications receiving most proposals were compared in detail. These showed different patterns in terms of the largest topical categories (Table 3, part A). For instance, in the Industrilandskapet application, $30 \%$ of the proposals concerned housing. Here citizens expressed that vacant lots should be occupied considering the need for centrally located housing. Conversely, only $6 \%$ of the proposals in the Kolkajen application concerned housing. Another example of large topical differences was found for commercial services. In the Årummet application, $16 \%$ of the proposals concerned the need for a wider range of stores, restaurants, cafés, etc. In comparison, commercial services were the focus

Table 3. Citizen proposals submitted in CityPlanner ${ }^{\mathrm{TM}}$ categorized according to (A) topic and (B) what change the proposal targets. Numbers are displayed for four applications and for the average of all ten applications.

\begin{tabular}{|c|c|c|c|c|c|}
\hline (A) Proposal concerning: & Industrilandskapet & Årummet & Trädgårdsstaden & Kolkajen & All \\
\hline Traffic/street & $14 \%$ & $25 \%$ & $19 \%$ & $24 \%$ & $23 \%$ \\
\hline Recreation/culture & $20 \%$ & $16 \%$ & $11 \%$ & $21 \%$ & $19 \%$ \\
\hline Park/nature & $10 \%$ & $10 \%$ & $10 \%$ & $15 \%$ & $13 \%$ \\
\hline Housing/real estates & $30 \%$ & $8 \%$ & $26 \%$ & $6 \%$ & $16 \%$ \\
\hline Commercial services & $8 \%$ & $16 \%$ & $7 \%$ & $4 \%$ & $9 \%$ \\
\hline Public services & $3 \%$ & $4 \%$ & $10 \%$ & $10 \%$ & $4 \%$ \\
\hline Other & $1 \%$ & $4 \%$ & $1 \%$ & $0 \%$ & $2 \%$ \\
\hline Multiple functions & $13 \%$ & $17 \%$ & $15 \%$ & $18 \%$ & $14 \%$ \\
\hline \multicolumn{6}{|l|}{ (B) Proposing something: } \\
\hline New, concrete & $66 \%$ & $77 \%$ & $55 \%$ & $64 \%$ & $64 \%$ \\
\hline New, avoid & $1 \%$ & $0 \%$ & $0 \%$ & $23 \%$ & $4 \%$ \\
\hline New, unspecified & $9 \%$ & $3 \%$ & $7 \%$ & $8 \%$ & $6 \%$ \\
\hline Current, complemented & $18 \%$ & $16 \%$ & $21 \%$ & $1 \%$ & $16 \%$ \\
\hline Current, maintain/restore & $5 \%$ & $3 \%$ & $11 \%$ & $0 \%$ & $6 \%$ \\
\hline No proposal & $2 \%$ & $1 \%$ & $5 \%$ & $3 \%$ & $4 \%$ \\
\hline
\end{tabular}


of just $4 \%$ of the proposals in the Kolkajen application. These examples demonstrate that when analyzing proposals submitted via OPTs, planners can relatively easy establish what issues citizens view as important and in what context the changes should take place.

The planners found the proposals citizens submitted through this OPT more constructive and of higher quality compared to those obtained through conventional public consultation. As a planning communicator stated:

Planners were a bit afraid early on, before we started working more digitally, that it would create extra work. But the views we have received have often been positive. When we have used aerial photos instead of common maps, 3D and high-resolution photos, then people have understood much better what we plan to do...before there were so many misunderstandings. People didn't understand where we should build or how. So many of the inputs that came in were not relevant.

It is still hard to draw general conclusions about how proposals are used practically in Norrköping. However, it is possible to assess examples. For proposals regarding Norrköping's comprehensive plan, proposals submitted through conventional planning procedures, such as written statements or oral comments on hearings, and proposals submitted by Cityplanner ${ }^{\mathrm{TM}}$ were approached differently by planners. While planners have answered each conventionally submitted input individually without relating them to each other, the more extensive inputs gained from Cityplanner ${ }^{\mathrm{TM}}$ were translated into general trends/areas and answered more comprehensively and with more vision. This signals that this OPT enables a more constructive analysis of citizen inputs. Rather than treating inputs as being critical of the plan, triggering defensive responses from planners, the inputs gained via the OPT were translated into functions highlighted in the city or what to generally avoid, as the following example from the consultation report for the comprehensive plan in Norrköping demonstrates:

Green and blue structure:

Build pedestrian walks around Motala Stream, move the parking spaces along the south side of the stream in the centre and preserve the greenery and the beach shelter in the city.

\section{Response:}

The value and significance of the green and blue elements in the city are highlighted in the plan proposal and the importance of ecosystem services is described more clearly. The proposal for urban beach zone is revised and the assessment of beach protection in urban development is clarified.
Another example concerns the building of a new park where the OPT triggered citizens to add concrete suggestions, building on other citizens' ideas, generating interest among planners and politicians to act. As explained by a planning communicator:

Some of the suggestions we have gained [using Cityplanner $^{\mathrm{TM}}$ ] have been very good and easy to implement like when we used it for the old industrial landscape. Then several [citizens] called a part "The love park". It was not called that before, but the name committee changed it so now it's called that officially on maps....Many also critically noted the lack of benches. So, the Technical Department bought benches and invited the person who submitted the proposal and he inaugurated the park.

These examples also relate to the second substantive value context; discussed by assessing whether proposals highlight contextual factors which facilitate planning. Results clearly demonstrate that, when invited, citizens submitted concrete suggestions (Table 3, part B). Almost $90 \%$ proposed tangible measures, related to both new functions and the current situation. The shares of concrete proposals related to the new and the current situations varied according to application-type. It was possible to obtain information about what citizens want to avoid if that is expressed in the questions posed. This was done in the Kolkajen case, explaining the high share of proposals specifying what should be avoided. The data contained very few proposals that were deemed irrelevant or unconstructive.

Furthermore, citizens are able to upload attachments to their proposal via CityPlanner ${ }^{\mathrm{TM}}$. This feature was used by $15 \%$ of the proposal submitters attaching photographs, sketches, markings on the map or reports. Drawings added on the digital map complemented the text in about $7 \%$ of the proposals. This facilitated descriptions of, e.g., where a pedestrian street should be located. About $5 \%$ of the proposals contained references to good, or in a few rare cases bad, examples. These serve both as "best practices" and more general references to attractive tourist destinations. The features of the OPT allowing such developed suggestions thus appear constructive for planning.

Planners in Norrköping were further asked about the abilities to act on citizen suggestions falling outside the scope of questions posed. Interviewees contended that planning, in general, is not yet ready to take full advantage of OPTs. This relates both to how departments should cooperate on citizen dialogues and when in the planning process the OPT should be used. Regarding the former, a planning information coordinator in Norrköping expressed that 'the different departments' communication strategies do not match", constraining the joint use of citizen inputs. To make better use of citizen deliberations, the various departments and planning projects would benefit from a common strategy establishing what com- 
munication channels should be used and how. Related to the latter, the different and often too separated planning projects would benefit from hosting common OPT applications. By focusing more on how a specific place/context relates to the various planning projects rather than on dividing the OPT applications by subject, the municipality could increase citizen participation and better capture proposals falling outside a specific project. As for now, the municipality is not able to manage comments outside a specific project, although Cityplanner ${ }^{\mathrm{TM}}$ does have the potential to provide this function.

\subsection{Instrumental Values}

To understand whether OPT deliberations give room for instrumental interpretations, this study assessed whether citizen proposals were used transparently; firstly in what stage of the planning process the applications were arranged and how they aimed to inform planning, and secondly if any systems for feedback to citizens or collective analyses were applied.

Related to timing, overwhelmingly, CityPlanner ${ }^{\mathrm{TM}}$ was used to invite proposals early on in the planning process, commonly when a city district was to be developed, rather than to replace formal dialogues. In a few other applications, this OPT was explicitly employed to generate ideas to be used in ongoing projects with specific focuses, such as future transport and urban green spaces. In four applications, it was employed to generate ideas at an early stage just prior to the formal planning process.

The questions posed generally invited a diverse range of inputs and the OPT was used transparently, i.e., showing all inputs provided and comments added. This suggests that the current OPT-usage counteracts justifications of pre-decided plans based on citizen inputs by their early application. Further, the aim of the deliberations was specified. This transparency may reduce the risk of instrumental interpretations (Stirling 2006, 2008) and of some inputs being hidden to promote specific interests (Kleinhans et al., 2015). If OPTs are to replace formal citizen dialogue, as some of the interviewed planners suggested, a high level of transparency needs to be maintained.

Related to feedback, however, the planners found that methods to transparently summarize and present citizen inputs and to provide feedback to citizens on how suggestions are utilized in planning were missing (Ertiö, 2015; Kahila-Tani et al., 2016). Lack of resources and time were recognized as constraints, as one planner responsible for a new city district accounted:

I understand that citizens feel that we give poor feedback on their points raised....It relates to the focus given to the dialogues. In many occasions, we are more pressured to bring forward the plans, and that cannot stall development. Then I think there's a risk that the citizen dialogues are negatively affected.
Several planners argue that more resources and a clearer mandate for how to involve citizens in planning is decisive for improving the feedback to citizens. Planners found it hard to balance early dialogue, aimed to obtain good citizen suggestions, with the formal planning process, allowing citizens to appeal against a plan:

Even though this creative forum [early dialogues through the Cityplanner ${ }^{\mathrm{TM}}$ tool] is good, we also have demands on this formal [procedure] that it should be possible to appeal against a plan from a legal perspective. Then we can have problems with this anonymous forum that Cityplanner ${ }^{\mathrm{TM}}$ gives.

Thus, though not dictated by law, citizens are often treated as commentators rather than co-producers of plans. Planners acknowledge that OPTs still have a complementary rather than a direct role in participatory planning. Developing the planning process to make better use of OPTs thereby includes approaching citizens as actors who can make plans better and more just, while preserving the transparency provided by OPTs. For improving citizen-feedback, planners suggested allowing for notifications of the status of various planning processes. Another way to improve feedback would be to develop OPTs to provide better summaries of citizen inputs (Kahila-Tani et al., 2016).

\section{Conclusions}

This study set out to analyze how a widely used Online Participatory Tool (OPT), Cityplanner ${ }^{\mathrm{TM}}$, affects normative, substantive and instrumental values of citizen participatory planning. When analyzing ten Swedish applications of this OPT, we find a large potential for improving normative value through: (i) generating more proposals than conventional methods; (ii) engaging a wider age-range and more even gender distribution; and (iii) increasing the interaction between citizens by facilitating the sharing of ideas on city improvement. However, the results indicate that the OPT may risk technical lockouts of the elderly in particular, and have, as with conventional methods, difficulties in attracting younger age groups. To sidestep technical lockouts, further development of citizen participation in local planning arrangements is needed (Afzalan et al., 2017; Stenberg et al., 2013). We recommend that the OPT should be combined with physical meetings, preferably through outreach activities at targeted locations and groups such as the elderly, young people, and migrants. This would be even more productive if combined with learning about the role of citizens in planning. We also recommend that planners make use of the OPT function to allow citizens to like/dislike other proposals. In fact, we suggest adding a function that allows users to directly comment on or further develop other proposals. This could spur debate and encourage learning. 
Related to substantive values, the proposals submitted through the OPT contributed to both the efficiency and context aspects. The vast majority of the OPTsubmitted proposals contained concrete suggestions for how and why to improve a location or urban function (c.f. Faehnle et al., 2014). Categorizing proposals into topics was efficient for establishing the main issues that citizens would like to improve/change. Each application got its own topical profile, which can be viewed as a representation of the planning context. Although topical categorizations are possible to perform, such analyzing or reporting function is not yet integrated into the OPT, which has been established also for other OPTs (Jankulowski et al., 2016). A reporting function would not only be important for planners but also for citizens. As Michels and De Graaf (2010) and Ertiö (2015) note, citizens ideally should take part in interpreting the results of the deliberation, shifting their role from passive proposal submitters to active co-creators of urban development, improving participation and transparency.

Related to instrumental aspects, this study shows that the OPT has currently been used early in, primarily, informal planning. Most, but not all applications, specify what urban planning processes the proposals contribute to. The OPT is more transparent than conventional methods because it shows all inputs provided and the resulting debates. However, the OPT applications do not specify when and how planners will make use of these proposals. To decrease the risk of instrumental use of citizen inputs, and to spur further citizen engagement, we recommend that OPTs contain a function that allows citizens to get feedback on how their input was used in concrete planning (c.f. Kahila-Tani et al., 2016). Moreover, planners suggest a chat-function to establish direct interaction between citizens and planners during OPT deliberations to increase transparency and facilitate learning.

In all applications, citizens made use of the OPT to comment on issues broader than the intended planning project. We find that planners struggle to handle these proposals. We suggest that joint applications of the OPT, that focus on a specific place rather than the different planning topics, would facilitate interaction between various urban planning projects and municipal departments and allow a larger uptake of citizen-proposals falling within their respective mandate. This could reduce the number of OPT applications and facilitate broad citizen engagement enabling better use of citizen proposals falling outside the scope of a delimited project. To do so, planners require more time allocated to citizen dialogue and a clearer assignment from politicians regarding how to invite and report to citizens on how proposals are used also outside of the scope of a specific plan proposal.

Judging from the above, the OPT to some extent seems to affect the division of roles between citizens, planners, and politicians. This OPT increases the interaction among citizens and encourages planners to cooperate across departments and planning projects and to rethink how to make use of the more diverse array of citizen proposals in planning. To reap these benefits, however, organizational changes are required. This study does not indicate that the OPT influences the interaction between citizens and politicians to any larger extent. Although it is possible for politicians and planners to get a better picture of how citizens perceive and want to develop their city, the applications of the OPT do not seem to stimulate any interaction across these boundaries, which is central in further OPT developments.

\section{Acknowledgements}

This research was supported by the Norrköping Research and Development Foundation and the Swedish Research Council Formas under Grant No. 942-2015-106.

\section{Conflict of Interests}

The authors declare no conflict of interests.

\section{References}

Afzalan, N., Sanchez, T. W., \& Evans-Cowley, J. (2017). Creating smarter cities: Considerations for selecting online participatory tools. Cities, 67, 21-30.

Blunkell, C. T. (2017). Local participation in coastal adaptation decisions in the UK: Between promise and reality. Local Environment, 22(4), 492-507.

Brown, G., \& Kyttä, M. (2014). Key issues and research priorities for public participation GIS (PPGIS): A synthesis based on empirical research. Applied Geography, 46, 122-136.

Burby, R. J. (2003). Making plans that matter: Citizen involvement and government action. Journal of the American Planning Association, 69(1), 33-49.

Conrad, E., Cassar, L. F., Christie, M., \& Fazey, I. (2011). Hearing but not listening? A participatory assessment of public participation in planning. Environment and Planning C, 29, 761-782.

Czepkiewicz, M., Jankowski, P., \& Młodkowski, M. (2017). Geo-questionnaires in urban planning: Recruitment methods, participant engagement, and data quality. Cartography and Geographic Information Science, 44(6), 551-567.

Ertiö, T-P. (2015). Participatory apps for urban planningSpace for improvement. Planning Practice \& Research, 30(3), 303-321.

Faehnle, M., Bäcklund, P., Tyrväinen, L., Niemelä, J., \& Yli-Pelkonen, V. (2014). How can residents' experiences inform planning of urban green infrastructure? Case Finland. Landscape and Urban Planning, 130, 171-183.

Fiorino, D. (1989). Environmental risk and democratic process: A critical review. Columbia Journal of Environmental Law, 14, 501-548.

Fung, A. (2006). Varieties of participation in complex governance. Public Administration Review, 66, 66-75. 
Fung, A. (2015). Putting the public back into governance: The challenges of citizen participation and its future. Public Administration Review, 75(4), 513-522.

Georgiadou, Y., \& Stoter, J. (2010). Studying the use of geo-information in government-A conceptual framework. Computers, Environment and Urban Systems, 34(1), 70-78.

Jankowski, P., Czepkiewicz, M., Młodkowski, M., \& Zwoliński, Z. (2016). Geo-questionnaire: A method and tool for public preference elicitation in land use planning. Transactions in GIS, 20(6), 903-924.

Kahila-Tani, M., Broberg, A., Kyttä, M., \& Tyger, T. (2016). Let the citizens map-Public participation GIS as a planning support system in the Helsinki Master Plan process. Planning Practice \& Research, 31(2), 195-214.

Kleinhans, R., Van Ham, M., \& Evans-Cowley, J. (2015). Using social media and mobile technologies to foster engagement and self-organization in participatory urban planning and neighbourhood governance. Planning Practice \& Research, 30(3), 237-247.

Legacy, C. (2017). Is there a crisis of participatory planning? Planning Theory, 16(4), 425-442.

Michels, A., \& De Graaf, L. (2010). Examining citizen participation: Local participatory policy making and democracy. Local Government Studies, 36(4), 477-491.
Poplin, A. (2012). Playful public participation in urban planning: A case study for online serious games. Computers, Environment and Urban Systems, 36, 195-206.

Russo, P., Lanzilotti, R., Costabile, M. F., \& Pettit, C. J. (2018). Towards satisfying practitioners in using Planning Support Systems. Computers, Environment and Urban Systems, 67, 9-20.

Schulz, D., \& Newig, J. (2015). Assessing online consultation in participatory governance: Conceptual framework and a case study of a national sustainabilityrelated consultation platform in Germany. Environmental Policy and Governance, 25, 55-69.

Stenberg, J., Abrahamsson, H., Benesch, H., Berg, M., Castell, P., Corkhill, E., Danielsson, S., Fridén, A., Styffe, R. H., Jadelius, L., Larberg, V., \& Tahvilzadeh, N. (2013). Framtiden är redan här: Hur invånare kan bli medskapare i stadens utveckling [The future is already here: How citizens can become co-creators of urban development]. Gothenburg: Majornas Grafiska AB.

Stirling, A. (2006). Analysis, participation and power: Justification and closure in participatory multi-criteria analysis. Land Use Policy, 23, 95-107.

Stirling, A. (2008). "Opening up" and "closing down". Power, participation, and pluralism in the social appraisal of technology. Science, Technology, \& Human Values, 33(2), 262-294.

\section{About the Authors}

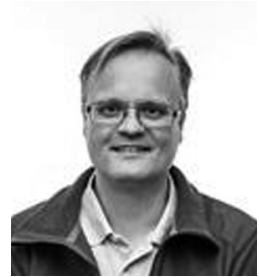

Mattias Hjerpe directs the Centre for Climate Science and Policy Research (CSPR) at Tema Environmental Change, Linköping University, Sweden. His main research interests are the triggers, barriers, arenas of local climate transitions and climate responses, how climate change is governed by local governments and municipal administrations and in urban planning as well as tools and measures for more inclusive urban planning. Hjerpe holds a PhD in Water and Environmental Studies from Linköping University.

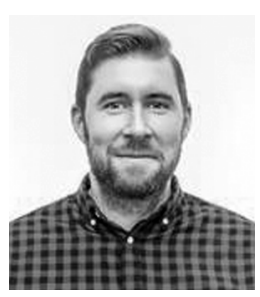

Erik Glaas is a Research Fellow at the Center for Climate Science and Policy Research and the Department of Thematic Studies, Linköping University, Sweden. His research interests include how local governments and municipal administrations approach climate change vulnerability, adaptation and transformation as well as development of interactive visualisations and citizen involvement in local planning. Glaas has a PhD in Water and Environmental Studies from Linköping University.

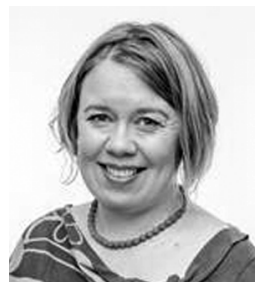

Sofie Storbjörk is a Senior Lecturer at the Center for Climate Science and Policy Research and the Department of Thematic Studies at Linköping University, Sweden. Her main research interest posits what imprint environmental and climate change concerns make in practical planning and decision-making as well as what limits and enables change; with a particular focus on planning and implementing climate adaptation. Storbjörk holds a PhD in Water and Environmental Studies from Linköping University. 